\title{
Binding affinity of five PBPs to Ostrinia sex pheromones
}

\author{
Tiantao Zhang ${ }^{1+}$, Yaqi Sun ${ }^{1,2+}$, Kevin W. Wanner ${ }^{3}$, Brad S. Coates ${ }^{4}$, Kanglai He $^{1}$ and Zhenying Wang ${ }^{1 *}$
}

\begin{abstract}
Background: Pheromone binding proteins (PBPs) of male Lepidoptera function in chemical communication, mate attraction and recognition. Directional selection was previously predicted between PBP3 orthologs of Ostrinia furnacalis and Ostrinia nubilalis were interpreted as being involved in sexual isolation.

Results: In vitro assays show that recombinant male OfurPBP3 bound $O$. furnacalis sex pheromones, Z-12-tetradecenyl acetate (Z12-14:OAC) and E-12-tetradecenyl acetate (E12-14:OAC), as well as to ECB pheromones Z11- and E1114:OAc. Recombinant OfurPBP4 and OfurPBP5 bound E11- and Z11-14:OAc with greater affinity compared to Z12- and E12-14:OAc, and OfurPBP4 incapable of binding with E12-14:OAc. In silico molecular docking predicted OfurPBP3 residues Phe12, lle52, Leu94, lle113 within a hydrophobic ligand-binding pocket and may participate in E12- and Z12-14:OAc binding. Independent site-directed mutagenesis experiments demonstrated that Ser12, Asn52, Arg94, and Asn 113 residues variants caused an approximately 1.7- to 4.6-fold reduction in OfurPBP3 affinity for Z12- and E1214:OAc, and a 2.7- to 8.4-fold decrease in affinity towards E11- and Z11-14:OAc.

Conclusions: Five PBPs of $O$. furnacalis play important functions in Ostrinia pheromones binding. These four amino acids may play a role in binding of sex pheromone, but this study does not address questions regarding specific response between males of $O$. furnacalis and $O$. nubilalis. Additional studies are required determine the role, if any, PBPs play in the evolution of sex pheromone communication.
\end{abstract}

Keywords: Pheromone binding protein, Binding, Sex pheromone, Docking, Mutant

\section{Background}

The sex pheromone detection by male moths (insect Order Lepidoptera) is highly sensitive and capable of detecting volatile hydrocarbons at low concentrations, as well as discriminating among stereoisomers and pheromone blends [1]. Female moths produce and emit volatile sex pheromones from pheromone glands located in distal segments of the abdomen, and perception can cause conspecific males to be attracted from a distance of $100 \mathrm{~m}$ [2]. The specificity of male reception and response to female sex pheromones is mediated by olfactory response neurons (ORNs) located in antennal trichoid sensilla.

\footnotetext{
*Correspondence: zywang@ippcaas.cn

TTiantao Zhang and Yaqi Sun contributed equally to this work

${ }^{1}$ State Key Laboratory for the Biology of the Plant Diseases and Insect

Pests, Institute of Plant Protection, Chinese Academy of Agricultural

Sciences, No. 2 West Yuanmingyuan Road, Beijing 100193, China

Full list of author information is available at the end of the article
}

Detection of female pheromones can induce physiological or behavioral changes in males following downstream signal transduction events mediated by the ORN [3]. The first step of pheromone detection is the transport of the hydrophobic pheromone across the hydrophobic lymph of the trichoid sensillum. Pheromone binding proteins (PBPs) are a subgroup of the odorant binding protein (OBP) family that have been reported in many species of Lepidoptera [4], and are hypothesized to be essential in environmental detection of sex pheromones by male moths [5]. PBPs are small, water-soluble, extracellular proteins that are found in the lymph surrounding the dendrites of pheromone-sensitive ORNs [6]. PBPs bind short to medium chain length fatty acid derivatives that enter the sensillum lymph through cuticular pores, and function as chaperones that transport pheromones to the sex pheromone receptors localized on the dendritic membranes of ORNs. PBPs have six highly conserved 
cysteine residues that help stabilize the globular protein and the internal hydrophobic binding pocket [7].

Nerve impulses are generated by ORNs following the delivery of sex pheromones by the PBPs are mediated by transmembrane odorant receptors (ORs) located on the surface of neuron dendrite. Insect ORs dimerize with a highly conserved co-receptor termed the odorant receptor co-receptor (Orco) to form a ligand-gated ion channel [8]. Pheromones are released from carrier PBPs when lower $\mathrm{pH}$ microenvironments are encountered at the neuron surface, where selectivity of PBPs may be enhanced [9]. Pheromone ligand release by PBPs and subsequent binding to the ORco $+\mathrm{OR}_{\mathrm{x}}$ complex will cause an electrical impulse to be generated [7]. Changes in the structure or function of these sexual communication pathway components form a hypothetical basis for the evolution of novel mechanisms of male attraction, and may be involved in establishment of sexual isolation between recently diverged species.

Species from the genus Ostrinia are models for the study of male sex pheromone detection systems. Different sex pheromone components are produced in the pheromone gland of females in the genus Ostrinia [1013], but different ratios of $E$-11- and $Z$-11-tetradecenyl acetate (E11- and Z11-14:OAc) predominate among most species. One exception is found with females of the Asian corn borer (ACB), O. furnacalis (Guenée), that produce and emit pheromone components that are synthesized with the double bond at the twelfth carbonyl carbon [14]; E-12- and Z-12-tetradecenyl acetate (E12and Z12-14:OAc). Mating between O. furnacalis and the closely related European corn borer (ECB), O. nubilalis (Hübner), occurs in the laboratory, but behavioral isolation and differences in response to sex pheromone may likely prevent high degrees of hybridization under natural conditions. The gene coding sequence of five PBPs were sequenced for both O. furnacalis and O. nubilalis, and with the exception of PBP3, the amino acid sequences between orthologs are highly conserved [15]. A significant overrepresentation of non-synonymous mutations predicted between PBP3 orthologs suggested a potential role in pheromone binding specificity between $E 11$ and Z11-14:OAc, and E12- and Z12-14:OAc [15]. In this study, we expressed and compared binding affinities of the five O. furnacalis PBP paralogs for synthetic female $O$. furnacalis and O. nubilalis pheromones, and mutagenized four amino acid residues predicted to coordinate E12- and Z12-14:OAc pheromones within the hydrophobic binding pocket. The data presented in this study are important for understanding the functional residues that are involved in effecter binding by Ostrinia PBP3, but does not attempt to address the evolutionary changes that impart divergent function between $O$. furacalis compared to O. nubilalis PBPs. Regardless, the data presented here are important for understanding the residues involved in general sex pheromone binding, but additional research is required to investigate any residues involved in the selectivity of OfurPBP3 compared to OnPBP3.

\section{Materials}

\section{RNA extraction and CDNA synthesis}

A laboratory colony of $O$. furnacalis was maintained at the Institute of Plant Protection, Chinese Academy of Agricultural Sciences. Pupae were allowed to emerge in a netted cage at room temperature, and moths were fed a $10 \%$ honey solution. Antennae were dissected from three day old male moths, immediately frozen in liquid nitrogen and stored at $-80{ }^{\circ} \mathrm{C}$ prior to use. Total RNA was extracted from O. furnacalis antennae using $\operatorname{Trizol}^{\mathrm{TM}}$ reagent (Invitrogen, USA) according to manufacturer instructions. RNA was then reverse transcribed into 1st strand $\mathrm{cDNAs}$ in a reaction primed with an oligod $\mathrm{T}_{18}$ oligonucleotide, and synthesized with Avian Myeloblastosis Virus (AMV) reverse transcriptase (Promega, USA) at $40{ }^{\circ} \mathrm{C}$ for $1 \mathrm{~h}$. The reaction was stopped by incubation at $95^{\circ} \mathrm{C}$ for $5 \mathrm{~min}$ and then cooling on ice for $20 \mathrm{~min}$.

The cDNA sequences for five Asian corn borer PBP genes were previously reported by Allen and Wanner [15, NCBI accession number range GU828024 to GU828028], and were used to design primer pairs that amplified the in frame mature gene coding sequence for each gene (omitting the signal peptide). Each primer incorporated a novel 5-prime overhang with palindromic sites for cleavage by BamHI (forward primer) or HindIII (reverse primer), which allowed for subsequent directional cloning into the restriction endonuclease sites of the multicloning site in the $\mathrm{pET} 30 \mathrm{a}(+)$ expression vector (Novagen, Darmstadt, Germany). Briefly, PCR primers for the amplification of mature OfurPBP1-OfurPBP5 coding sequences were designed using Primer3 [16] with a minimum length of 19 nucleotides and a predicted melting temperature $(\mathrm{Tm})$ of $\geq 58{ }^{\circ} \mathrm{C}$. The 5 -prime extensions that encompassed the Bam HI preceding the $\mathrm{N}$-terminal CDS and HindIII site following the C-terminal coding region were inserted manually, the details of the primers was shown in Additional file 1: S1. The subsequent PCR reactions used 5 pmol of each primer used $1.0 \mu \mathrm{l}$ of cDNA template diluted 1:10 with the high fidelity polymerase (Takara, Japan). Thermal cycling was performed on a Biometra T-Gradient thermocycler (Biometra, Göttingen, Germany) under the following conditions: $94{ }^{\circ} \mathrm{C}$ for $2 \mathrm{~min} 30 \mathrm{~s}, 35$ cycles of $94{ }^{\circ} \mathrm{C}$ for $30 \mathrm{~s}, 58^{\circ} \mathrm{C}$ for $30 \mathrm{~s}$, and $72{ }^{\circ} \mathrm{C}$ for $1 \mathrm{~min}$, and $72{ }^{\circ} \mathrm{C}$ for $10 \mathrm{~min}$. An aliquot of each PCR product was separated on a $1.5 \%$ agarose gel containing $0.5 \mu \mathrm{g} \mathrm{ml}^{-1}$ ethidium bromides and visualized 
under UV illumination. PCR products were cloned into the pGEM-T vector (Promega, Madison, WI), and single clones were obtained after selection on LB agar plates containing $50 \mu \mathrm{g} \mathrm{ml}^{-1}$ ampicillin. For each OfurPBP clone, plasmid DNA isolated and sequenced from the T7 primer binding site at Beijing SinoGenoMax Co., Ltd (Beijing, China) on an ABI 3730XL DNA Analyzer (Applied Biosystems, Foster City, CA, USA). Electropherogram data were compared to cDNA sequences of respective PBPs in GenBank accessions GU828024 to GU828028 previously published by [15] using Vector NTI software (Life Technologies, Grand Island, NY). Independent multiple sequence alignments were made using OfurPBP1 to OfurPBP5 sequences generated in this study, O. furnacalis (GU828024.1 to GU828028.1), O. nubilalis E-strain (GU828019.1 to GU828023.1), and O. nubilalis Z-strain (GU826166.1 to GU826170.1) using the Clustal W algorithm (gap opening penalty 15, gap extension penalty 6.66 , weight matrix IUB, and transition weight of 0.5).

\section{Prokaryotic expression and purification}

The pGEM plasmid inserts were excised using BamHI and HindIII double digestion, excised from a 1\% agarose gel and fragments purified using Nucleic Acid Purification Kit (Axygen, USA). The BamHI and HindIII digestion products for OfurPBP1 to OfurPBP5 were then ligated individually into BamHI and HindIII cut and dephosphorylated pET30a $(+)$ vector by incubation with T4 Ligase (Promega) for $4 \mathrm{~h}$ at $16{ }^{\circ} \mathrm{C}$. Recombinant $\mathrm{pET} 30 \mathrm{a}(+)$ vectors containing inserts derived from the five pheromone binding proteins (OfurPBP1-OfurPBP5) were used to transform BL21(DE3) Escherichia coli cells by electroporation, and cells allowed to recover in SOC medium for $1 \mathrm{~h}$ at $37{ }^{\circ} \mathrm{C}$. Transformed cells were selected by spread plating on LB agar plates containing $25 \mu \mathrm{g} \mathrm{m} l^{-1}$ kanamycin sulfates as described by the manufacturer. Positive clones were cultured, and plasmid DNA isolated and inserts sequenced using the T7 primer as described above.

Positive pET30a $(+)$ clones containing correct insert DNA from each of the PBP sequences were incubated separately in fresh liquid LB medium containing $25 \mu \mathrm{g} \mathrm{ml}^{-1}$ kanamycin sulfate. Cultures were shaken at $37{ }^{\circ} \mathrm{C}$ until the optical density (OD) of each culture reached to $0.6-0.8$, where OD was measured on a Shimadzu spectrophotometer (Shimadzu, Japan). Protein expression was induced in each culture by the addition of isopropyl- $\beta$-D-1-thiogalactopyranoside (IPTG) to a final concentration of $0.1 \mathrm{mM}$, followed by incubation on a $150 \mathrm{rpm}$ shaker at $37^{\circ} \mathrm{C}$ for $6 \mathrm{~h}$. The cells were harvested by centrifugation at $7500 \times g$ for $15 \mathrm{~min}$ at $4{ }^{\circ} \mathrm{C}$, chilled on ice, and treated with ultrasonic disruptor.
After centrifugation, all five proteins were highly present in inclusion bodies. The protein pellets were suspended using previously published methods [17]. Proteins were purified by application of the lysate to Ni-NTA columns and purified as specified by the manufacturer (Qiagen, Germany), followed by digestion of eluted proteins with enterokinase to remove the His tag. Protein preparations were desalted by dialysis, quantified by means of the Bradford method [18], and purity verified by SDS-PAGE.

\section{Pheromone-binding affinity}

Initial measures of the binding affinity of the fluorescent ligand $N$-phenyl-1-naphthylamine (1-NPN) to recombinant OfurPBP1, OfurPBP2, OfurPBP3, OfurPBP4 and OfurPBP5 was determined by titrating to final concentrations of 1.0-12.0 $\mu \mathrm{M} 1-\mathrm{NPN}$ with $2 \mu \mathrm{M}$ of each protein in $1.0 \mathrm{ml} 50 \mathrm{mM}$ Tris- $\mathrm{HCl}, \mathrm{pH} 7.4$ and $\mathrm{pH}$ 4.0. The 1-NPN probe was excited at $337 \mathrm{~nm}$, and emission spectra were recorded between 380 and $450 \mathrm{~nm}$ on a Shimadzu fluorescence spectrophotometer (Shimadzu, Japan). Each trial was run in triplicate, and Scatchard plots of the ratio of bound to unbound ligand were created using Microsoft Excel 2010. Competitive binding assays were performed with each of the OfurPBPs using 1-NPN as the probe. Assay reactions were comprised of $2 \mu \mathrm{M}$ of each OfurPBP diluted individually in $2.0 \mathrm{ml} 20 \mathrm{mM}$ Tris- $\mathrm{HCl}$, $\mathrm{pH}$ 7.4, which were then titrated with $1.0 \mathrm{mM}$ increments sex pheromone diluted in methanol to a final concentrations of $1-6 \mu \mathrm{M}$. The synthetic standards that correspond to the sex pheromones of $O$. furnacalis, $O$. nubilalis and other lepidopteran species were purchased from SigmaAldrich (Shanghai, China; Additional file 2: S2). Excitation and emission spectra were recorded from triplicate assays as described above. The binding affinity of each purified OfurPBP to the different sex pheromones was measured by calculation of binding constants via competitive fluorescence-binding assay. In brief, relative fluorescent intensities were analyzed by GraphPad Prism 5 software (GraphPad Software Inc, La Jolla, CA) and calculation was done using the equation: $\mathrm{Ki}=[\mathrm{IC50}] /$ $\left(1+[1-\mathrm{NPN}] / \mathrm{K}_{1-\mathrm{NPN}}\right)$, where $[1-\mathrm{NPN}]$ is the free concentration of 1-NPN and $\mathrm{K}_{1-\mathrm{NPN}}$ is the dissociation constant of the complex protein/1-NPN [19, 20]. Sex pheromone binding affinity with different PBPs was analyzed using One-way ANOVA in SAS 8.0 (SAS Institute Inc., Cary, NC, USA).

\section{Molecular modeling and ligand docking}

The amino acids of OfurPBP3 were submitted to SWISSMODEL tool to automate homology-modeling [21]. The sequence of OfurPBP3 was compared to all the known protein sequences and that had a high similarity with the target sequence on RCSB Protein Data Bank (PDB) 
(www.rcsb.org). The OfurPBP3 used AtraPBP1 for a homology model [22]. The main pheromone components of O. furnacalis, Z12- and E12-14:OAc were used respectively in molecular docking with the simulated model of OfurPBP3 based on the advanced docking program CDOCKER [23]. Molecular dynamics scheme based on CHARMm was used to dock ligands into a binding site in the CDOCKER program. Total interaction $\left(E_{\text {total }}\right)$, Van der Waals $\left(E_{\mathrm{vdw}}\right)$, and electrostatic interaction energies $\left(E_{\text {ele }}\right)$ were calculated for all OfurPBP3 residues predicted to be involved in the binding of intraspecific sex pheromone components.

\section{Site-directed mutagenesis}

Four amino acids of OfurPBP3 with some of the most negative estimated $E_{\text {total }}$ values were mutated using Quick-change lightning site-directed mutagenesis kit (Stratagene, La Jolla, CA, USA); Ile to Asn at position 113 (I113A), m2 Phe to Ser at position 12 (F12S), m3 Ile to Asn at position 52 (I52N), and $\mathrm{m} 4 \mathrm{Leu}$ to Arg at position 94 (I94R). The sequence of each primers used to alter the aforementioned sites by nucleotide mismatch are shown in Additional file 3: S3. After initial denaturation at $94{ }^{\circ} \mathrm{C}$ for $5 \mathrm{~min}$, the subsequent PCR followed with 30 cycles of $94{ }^{\circ} \mathrm{C}$ for $30 \mathrm{~s}, 56{ }^{\circ} \mathrm{C}$ for $30 \mathrm{~s}$, and final extension at $72{ }^{\circ} \mathrm{C}$ for $1 \mathrm{~min}$. Changes within site-directed mutant fragments were verified by cloning into the pGEM-T Easy vector (Promega) by Sanger sequencing. All mutated OfurPBPs proteins were expressed and used within in vitro binding assays as described above.

\section{Results}

\section{RNA extraction and CDNA synthesis}

Five amplified fragments predicted to contain the mature OfurPBP1 to OfurPBP5 gene coding sequences were successfully amplified by RT-PCR (approximate $450 \mathrm{bp}$ in size; gel data not shown), cloned into the pGEM vector, and Sanger sequenced. Multiple nucleotide sequence alignments of these cloned OfurPBP sequences showed 100\% similarity with homologous regions of GenBank accessions for O. furnacalis PBP1 to PBP5 previously identified by Allen and Wanner [15]. One exception was predicted in a single nucleotide polymorphism at position 474 of OfurPBP2 which changed a guanine (G) in GU828025.1 to an adenosine (A) in our cloned OfurPBP2 sequence. This SNP on $O f u r P B P 2$ produced a synonymous mutation, such that the amino acid sequence was unchanged and the same as that reported by Allen and Wanner [15].

\section{Prokaryotic expression and purification}

Five mature OfurPBP gene coding sequences were successfully excised from pGEM, and re-inserted into to the pET30a $(+)$ expression vector. End sequencing of inserts from the $\mathrm{T} 7$ primer binding site flanking the pET30a $(+)$ vector multicloning site confirmed the correct orientation and sequence of each OfurPBP insert (data not shown). Each of the IPTG induced cultures derived from E. coli $\mathrm{pET} 30 \mathrm{a}(+)-O f u r P B P$ transformants showed high expression of a His-tagged fusion protein in the approximately $16-19 \mathrm{kDa}$ size range (Fig. 1, lane 4 ), and subsequent purification of each on Ni-NTA columns successfully removed visible endogenous $E$. coli proteins (Fig. 1, lane 5). Digestion of purified OfurPBPs fusion proteins with enterokinase (to remove the Histags) resulted in decreased estimated molecular weights, which were less than the $15-17 \mathrm{kDa}$ predicted for fulllength lepidopteran PBPs containing leader peptides (Fig. 1, lane 6). This was expected since the cloned fragments were devoid of leader peptides and represent fully functional processed peptides. After analysis, most of the proteins were expressed in inclusion bodies. Bradford assays estimated the concentration of each purified OfurPBP protein at $\sim 1$ to $2 \mu \mathrm{g} \mathrm{ml}^{-1}$, and extracts were used for the further experiments in this study.

\section{Pheromone-binding affinity}

The general affinity of the 1-NPN reporter for each OfurPBP was measured (Fig. 2a), and a regression of these titrated values were plotted within Scatchard plots and showed a linear relationship. Next, the binding specificity of 6 different Ostrinia pheromone components were tested against each recombinant $O$ furPBP in competitive binding assays with 1-NPN as the reporter (Additional file 2: S2). The female sex pheromones, Z12- and E12-14:OAc are produced by O. furnacalis and Z11- and E11-14:OAc by O. nubilalis (see "Background" section). Competitive binding assay results showed that Z12and E12-14:OAc bound most strongly with OfurPBP3 $\left(K_{\mathrm{i}} \leq 2.86 \pm 0.04\right)$, and also showed affinity for OfurPBP1 and OfurPBP2 $\left(\mathrm{K}_{\mathrm{i}}=5.01 \pm 0.14\right.$; Table 1; Fig. 2). Results also showed that Z12-14:OAc bound OfurPBP5 weakly and E12-14:OAc had no detectable binding to OfurPBP4. In contrast, both Z11- and E11-14:OAc pheromones from $O$. nubilalis showed relatively high affinities for all five OfurPBPs (Table 1; Fig. 2), with estimates of Z1114:OAc binding to OfurPBP4 being the highest for all those that were tested $\left(\mathrm{K}_{\mathrm{i}}=1.09 \pm 0.05\right)$. Additionally, the O. nubilalis pheromone E11-14:OAc bound strongly to OfurPBP5 $\left(\mathrm{K}_{\mathrm{i}}=1.14 \pm 0.04\right)$, and showed a significantly greater affinity compared to either Z12- and E1214:OAc from $O$. furnacalis $\left(K_{\mathrm{i}}=6.80 \pm 0.47\right)$. All five recombinant OfurPBPs showed weak or lack of detectable binding to the interspecific lepidopteran sex pheromones, Z9-14:OH and E11-14:OH. However, under the $\mathrm{pH} 4.0$, none of the OfurPBPs showed any binding to the sex pheromones that were tested (data not shown). 


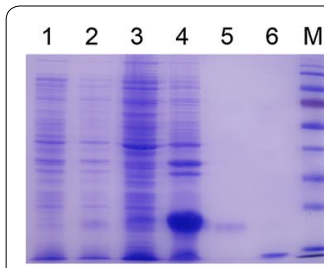

a

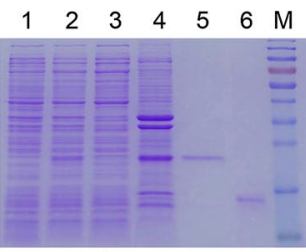

b

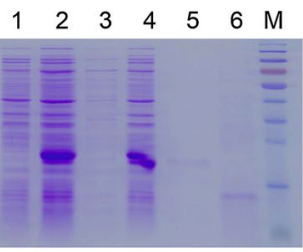

C

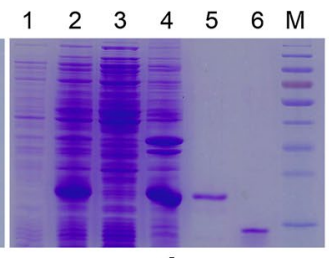

d

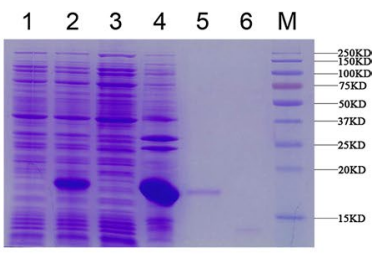

e

Fig. 1 SDS-PAGE analysis of recombinant Ostrinia furnacalis pheromone binding proteins (PBPs) induced from E. coli clones carrying in frame insertions of OfurPBP1, OfurPBP2, OfurPBP3, OfurPBP4, or OfurPBP5 coding sequences in the PET30a(+) expression vector. Replicate gel lanes correspond to (1) cell culture prior to addition of isopropyl- $\beta$-D-1-thiogalactopyranoside (IPTG), (2) IPTG induced cells at O.D. 0.6-0.8, (3) supernatant after ultrasonic treatment and centrifugation, (4) pellet after ultrasonic treatment and centrifugation, (5) Ni-NTA column purified proteins, and (6) enterokinase digested products with His-tags cleaved. M corresponds to molecular weight marker. a OfurPBP1; b OfurPBP2; c OfurPBP3; d OfurPBP4; e OfurPBP5
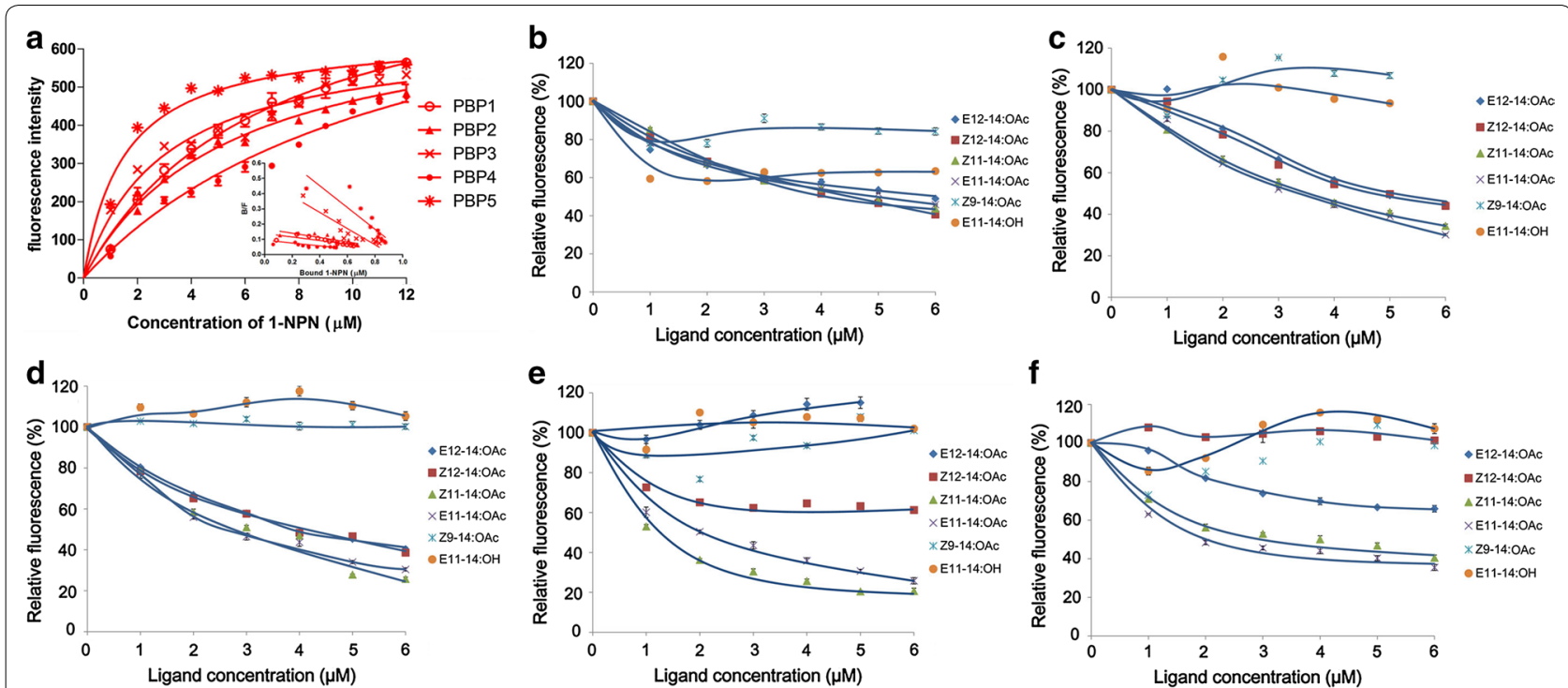

Fig. 2 Binding curves. a Binding curves and Scatchard plots (inset) for fluorescent probe 1-NPN binding with purified Ostrinia furnacalis pheromone binding proteins (OfurPBPs) at pH 7.4. Competitive binding curves for different synthetic sex pheromone hydrocarbons (ligands) at pH 7.4 to each of the OfurPBPs, b OfurPBP1, c OfurPBP2, d OfurPBP3, e OfurPBP4, and $\mathbf{f}$ OfurPBP5. The different sex pheromones tested are listed in Additional file 2: $\mathrm{S} 2$

\section{D modeling and docking}

The OfurPBP3 was successfully modeling with AtraPBP1 by using of SWISS-MODEL tool (Fig. 3a). This figure visual displayed the 3-dimensional structure of OfurPBP3. The QMEAN and GMQE were used to quality estimation, all the score reflected the expected accuracy of OfurPBP3 built with the alignment and template of AtraPBP1. Based on the consideration of hydrophobicity at their binding site, ligand poses and consensus score programs were executed to evaluate binding pose affinities for the residues. Subsequently, optimal 3D binding conformations to the main sex pheromone components, Z12- and E12-14:OAc, were shown in Fig. 3c, d. The interaction energies $E_{\text {total }}, E_{\mathrm{vdw}}$, and $E_{\text {ele }}$ between OfurPBP3 amino acids that interact with Z12- or E12-14:OAc were estimated (Table 2). Results indicated that Phe12 and Leu94 interacted most strongly with Z12-14:OAc. and Phe12 and Ile52 with E12-14:OAc.

\section{Site-directed mutagenesis}

Based on the molecular modeling and docking results four amino acid residues with among the highest $E_{\text {to- }}$ tal were chosen (Phe 12, Ile52, Leu94 and Ile113), and in vitro mutagenesis altered OfurPBP3 mutants F12S, I52N, I94R, and I113N verified from Sanger sequencing results (Additional file 4: S4). Subsequent competitive binding assays demonstrated that all OfurPBP3 mutants showed reduced affinities towards Z11- and E11-14:OAc 


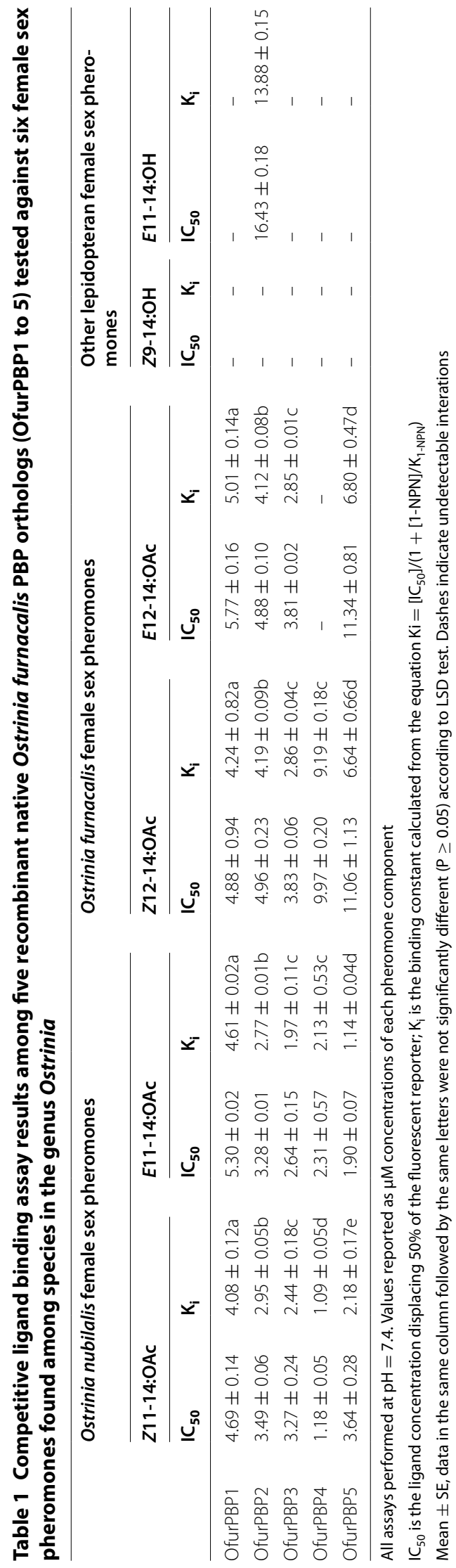




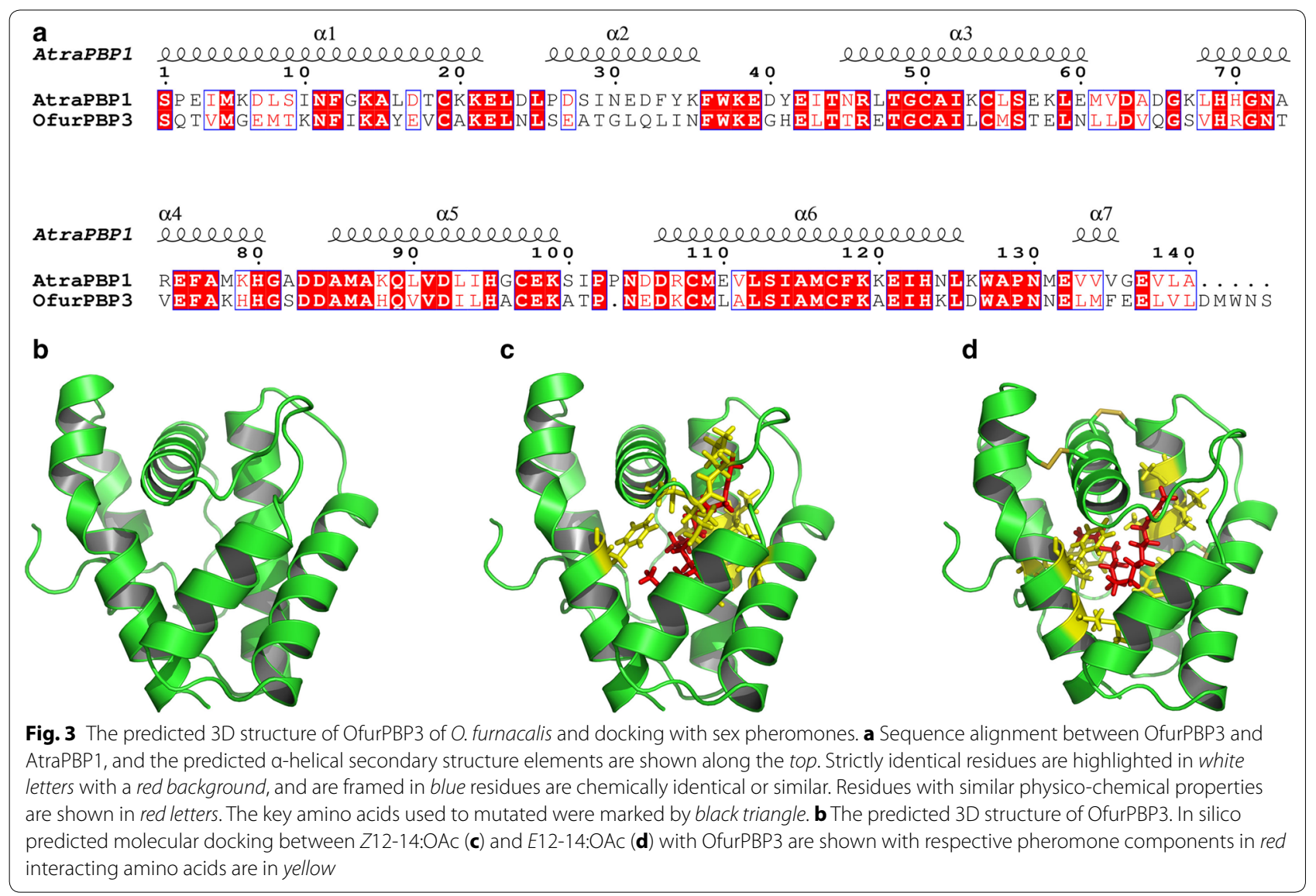

(8.53-20.11 $\mu \mathrm{M})$ and Z12- and E12-14:OAc (4.89$18.77 \mu \mathrm{M}$; Table 3) compared to the wild-type OfurPBP3. Among the mutants, I113N and F12S had the least dramatic effect on affinity towards Z12-14:OAc ( 2-fold reduction). Surprisingly I113N showed a nearly 8.25fold reduction in Z11-14:OAc binding compared to the wildtype, and represented the greatest degree of change among all the assays. All mutated OfurPBPs showed the capacity to bind the sex pheromones components of other lepidopteran females, $Z 9-14: \mathrm{OH}$ and $E 11-14: \mathrm{OH}$ (Table 3), compared to the wildtype which failed to demonstrate this function. In particular, I113N demonstrated the ability to bind $Z 9: 14-\mathrm{OH}$, which is a known antagonist of male response to $E 11$ - and Z11-14:OAc as well as E12- and Z12-14:OAc (see "Discussion" section).

\section{Discussion}

We showed that the five recombinant OfurPBPs have a range of binding affinities with synthetic $O$. furnacalis sex pheromones, and that OfurPBP2 and OfurPBP3 bind Z12- and E12-14:OAc with the greatest affinity (Table 1; Fig. 2). These binding results might suggest that female $O$. furnacalis pheromones are bound strongly to maleantennal expressed OfurPBP2 and OfurPBP3 in vivo, and that these two chaperones could play a role in the specific transport of Z12- and E12-14:OAc within the sensillar lymph [15]. The highly biased expression of OfurPBP2 and OfurPBP3 transcripts in the Ostrinia male compared to female antennae has been used to suggest possible roles in the binding of female sex pheromones [15], and the latter hypothesis was corroborated for the first time by our data (Table 1). The correlation between PBP expression level and molecular function was further corroborated by OfurPBP4 and OfurPBP5, wherein both show female biased expression (e.g. low expression in male antennae; Allen and Wanner [15]) and have weak or undetectable binding affinities towards E12- and Z12-14:OAc (Table 1). A difference in pheromone binding affinity has been previously shown for PBP1 from $A$. polyphemus and A. pernyi which were both bound strongly by $E 4,9 Z-14: A c$, but PBP2 and PBP3 from these species preferentially bound E6,11Z-16:Ald and E4,9Z14:Ac, respectively [24]. Analogously, PBP1 and PBP2 from Lymantria dispar male antennae respectively bind specifically to $(+)$ and $(-)$ enantiomers of the pheromone released by conspecific females [25], which suggest that PBP gene family members can develop variant molecular functions and that our observed differences between 
Table 2 Interaction energies between OfurPBP3 amino acid residues predicted to interact with Z12- and E12-14:0Ac

\begin{tabular}{|c|c|c|c|c|c|c|}
\hline \multirow[t]{2}{*}{ Residues } & \multicolumn{3}{|l|}{$Z 12-14: O A C$} & \multicolumn{3}{|c|}{ E12-14: OAC } \\
\hline & $E_{\text {total }}$ & $E_{\mathrm{vdw}}$ & $E_{\text {eie }}$ & $E_{\text {total }}$ & $E_{\mathrm{vdw}}$ & $E_{\text {eie }}$ \\
\hline Met5 & -0.640547 & -0.59189 & -0.04866 & -0.25078 & -0.48178 & 0.231002 \\
\hline Met8 & -2.03208 & -1.93288 & -0.0992 & -2.08551 & -1.95942 & -0.12609 \\
\hline Thr9 & -0.725306 & -0.69731 & -0.028 & -0.99693 & -0.94188 & -0.05505 \\
\hline Phe12 ${ }^{\mathrm{a}}$ & -3.44675 & -3.59075 & 0.144002 & -6.12711 & -6.37345 & 0.246336 \\
\hline Trp37 & -0.265347 & -0.34278 & 0.077433 & -3.00745 & -2.93172 & -0.07573 \\
\hline Ile $52^{\mathrm{a}}$ & -2.06826 & -1.91544 & -0.15282 & -1.04584 & -1.05974 & 0.013902 \\
\hline Leu53 & -0.602925 & -0.69798 & 0.095052 & -3.66956 & -3.21571 & -0.45385 \\
\hline Ser56 & -2.3887 & -2.1026 & -0.2861 & -1.34568 & -1.50106 & 0.155383 \\
\hline Leu61 & -2.80413 & -3.02047 & 0.216336 & -1.89133 & -2.01921 & 0.127883 \\
\hline Thr73 & -0.502607 & -0.6027 & 0.100092 & -0.85839 & -0.52394 & -0.33445 \\
\hline Phe76 & -1.22346 & -1.2791 & 0.055643 & -1.40333 & -1.4029 & -0.00043 \\
\hline Val90 & -0.59213 & -1.00189 & 0.40976 & -0.71638 & -0.44384 & -0.27254 \\
\hline Leu94 ${ }^{\mathrm{a}}$ & -3.31952 & -3.46491 & 0.145392 & -2.20259 & -2.17874 & -0.02385 \\
\hline Ala110 & -2.27602 & -2.23154 & -0.04448 & -2.29651 & -1.83678 & -0.45973 \\
\hline Ile113 & -4.09863 & -4.16508 & 0.066446 & -2.37414 & -2.46977 & 0.095626 \\
\hline Ala114 & -2.21266 & -2.52149 & 0.308827 & -2.80034 & -2.36719 & -0.43315 \\
\hline Phe117 & -2.81675 & -3.782 & 0.965255 & -3.08384 & -3.35722 & 0.273382 \\
\hline Met133 & -0.604454 & -0.6274 & 0.022947 & -2.5398 & -2.6934 & 0.153598 \\
\hline
\end{tabular}

$E_{\text {total }}$ : total interaction energy; $E_{\mathrm{vdw}}$ : Van der Waals energy; $E_{\text {ele }}$ electrostatic interaction energy

a Residues chosen for site-directed mutagenesis

OfurPBP2 and OfurPBP3 compared to OfurPBP4 and OfurPBP5 may not be surprising. Furthermore, the binding affinities of OfurPBP1, OfurPBP2, and OfurPBP3 to cognate pheromone components estimated in this study are comparable to analogous Ki values estimated for Helicoverpa armigera PBPs (Ki values $1.2-5.2 \mu \mathrm{M}$ ) and $H$. assulta $(0.7-4.1 \mu \mathrm{M})$ to their corresponding sex pheromone [26]. Similarly, the binding affinities of the cockroach Leucophaea maderae PBP, PBPLma, to their sex pheromones 3-hydroxy-butan-2-on or butane-2,3-diol were 3.8 and $2.5 \mu \mathrm{M}$, respectively [27].

In contrast to predictions made by Allan and Wanner (2010), OfurPBP3 did not show specific affinity towards $Z 12$ - and $E 12-14: O A c$, but instead demonstrated a nearly equal affinity for Z11- and E11-14:OAc emitted by $O$. nubilalis females. Moreover, all OfurPBPs showed a comparatively strong affinity towards Z11- and E11-14:OAc, including observation of strong binding by $O f u r P B P 4$ and OfurPBP5. These ligand affinities are in direct opposition to species responses [28], which might suggest that OfurPBPs bind to Z11- and E11-14:OAc does not preclude a role in male sexual response, but only in potential for binding these components within the sensillar lymph. Transcripts encoding PBPs have previously been found in non-pheromone sensitive female antennae and male sensilla $[29,30]$, which suggests that PBPs may have evolved alternate roles such as host plant recognition [31]. This notion was reinforced by evidence that compounds structurally similar to cognate pheromones can be bound by Bombyx mori PBP1 [32], and further by observations that of sex pheromones and plant volatiles can interact within the same peripheral sensory pathways [33, 34]. This altogether suggests that binding compounds or interspecific pheromone components to a PBP does not preclude subsequent interaction with the $\mathrm{ORco}+\mathrm{OR}_{\mathrm{x}}$ complex resulting in sexual response. Grosse-Wilde et al. [35] showed that pheromone agonists bound to different PBP paralogs and lead to different responses by male sexuallyresponding ORco $-\mathrm{OR}_{\mathrm{x}}$ receptors, such that members of the PBP gene family may have evolved specific interactions at different $\mathrm{ORco}-\mathrm{OR}_{\mathrm{x}}$ complexes. The O. furnacalis OR3 (OfOR3) was shown to specifically respond to Z12-14:OAc and E12-14:OAc [36]. The selectivity of PBP for delivery of these pheromone components to OfOR3 was not investigated in this or any other previous studies, but may provide crucial information regarding the evolution of species-specific male sexual response. Regardless, our results are the first to demonstrate that male antennal expressed OfurPBP2 and 3 are capable of binding the intraspecific female pheromone components Z1214:OAc and E21-14:OAc.

A change in the 3-dimensional conformation of PBPs occurs following a shift from neutral to acidic $\mathrm{pH}$ environments, and is associated with binding and release of 


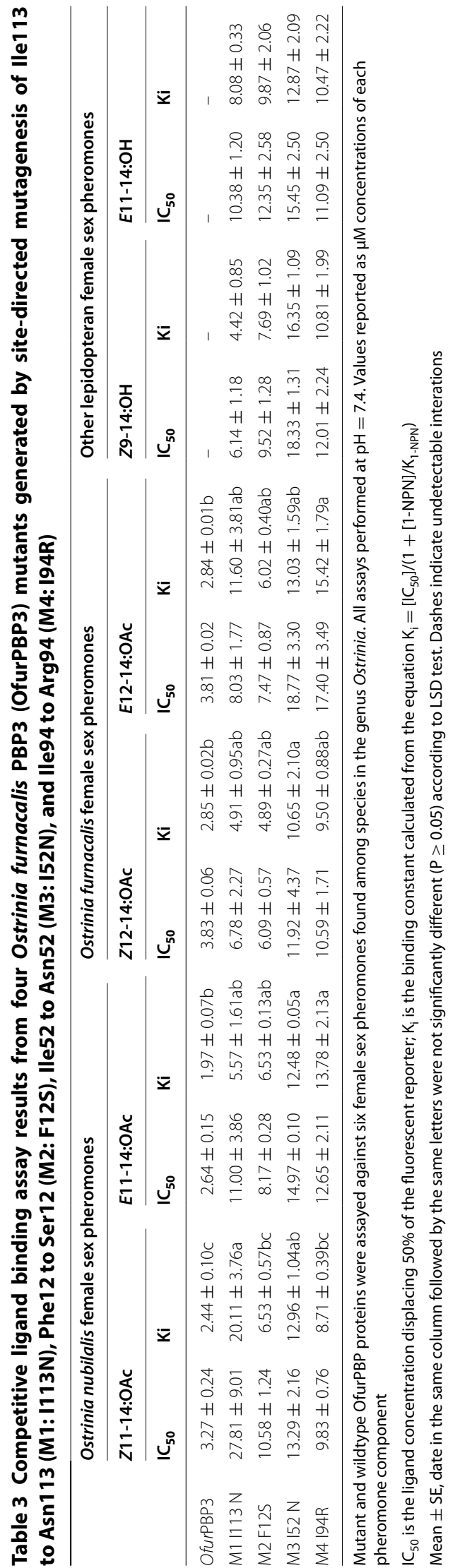


cognate pheromone ligands. Crystal structures of pheromone-bound PBPs indicated that the C-terminal amino acid sequence remains linear under neutral $\mathrm{pH}$ [37], whereas this C-terminal region forms an alpha-helix in acidic conditions [alpha helix $7, \alpha 7 ; 37,38$ ]. The more linear conformation with 6 alpha helices was used to predict the 3D structure of OfurPBP3 (Fig. 3b), wherein 18 residues within the hydrophobic binding pocket were predicted to interact with Z12-14:OAc and E21-14:OAc (Table 2). This $\mathrm{pH}$-dependent change is also accompanied by alteration of PBP 3-dimensional structure where salt bridges are formed between two Asp residues on the C-terminal $\alpha 7$ helix and two corresponding deprotonated His residues in the pheromone binding pocket at low $\mathrm{pH}$. Thus, the $\mathrm{pH}$-dependent alpha-helix interactions with the pheromone binding pocket competes with sex pheromone ligands, and is a key component for PBP pheromone carrier and delivery functions. Specifically, neutral $\mathrm{pH}$ in sensillar lymph may place PBPs into a competent pheromone-binding state, where these chaperones are capable of transporting hydrophobic pheromone hydrocarbons.

Residues of OfurPBP3 potentially involved during the binding of intraspecific pheromones at neutral $\mathrm{pH}$ binding are important for understanding function within a species, and the $E_{\text {Total }}$ derived from CDOCKER predicted the 18 key amino acids which may interact with $Z 12$ - and E12-14:OAc ligands (Table 2). Predictions from homology-based in silico structural modeling can be unreliable [21] and translation into biological systems can be bolstered by experimental validation. Thus, site-directed mutagenizes of four residues with the highest $E_{\text {total }}$ values were made in four separate mutant OfurPBPs. Comparisons between wildtype and mutant OfurPBPs clearly demonstrated the negative affects on binding affinities following change of native residues to those with different polar properties and suggest that Phe12, Ile52, Ile94, and Ile113 are important for the efficient binding of cognate sex pheromones. Interestingly, after mutation, the OfurPBPs showed weak binding affinity towards other lepidopteran female sex pheromone, Z9-14:OH and E1114:OH, that was not observed with the wild type OfurPBP3. These differences may occur either through direct interaction with the bound hydrocarbons, or by stabilization of the hydrophobic binding pocket. The affects of induced amino acid changes on the overall 3D structure and function of a protein remain largely unknown [39]. This suggests that even single amino acid changes might alter PBP conformation in unforeseen ways, such that further research, such as using $\mathrm{x}$-ray or NMR to analyze the structure of native and mutant binding proteins are likely required. Although our current study demonstrated the ability of OfurPBPs to bind inter and intraspecific sex pheromones, further research is likely required to fully understand the structural, chemical, and environmental factors that may influence any specific interactions between PBPs and their cognate sex pheromones.

\section{Conclusions}

Our research provides crucial functional information regarding the specificity of PBPs in an Ostrinia moth species, which is a group that has emerged as a model for the study of sexual communication systems in Lepidoptera. This study provides the first biochemical evidence that OfurPBP2 and OfurPBP3 bind Z12- and E12-14:OAc with high affinity. Moreover, this current work demonstrates that despite prior evidence for directional selection and predicted divergent function between OnPBP3 and OfurPBP3, the latter shows a nearly equal affinity to O. furnacalis female Z12- and E12-14:OAc and O. nubilalis Z11- and E11-14:OAc. The four amino acids, Ser12, Asn52, Arg94, and Asn113 may play a role in binding of sex pheromone of PBP3, but cannot be interpreted in the context of species-specific binding since we only mutagenized sites predicted to be important in protein interactions with pheromone ligands. Our results suggest that overall individual $O$. furnacalis PBPs may be capable of equivalent binding of both intra- and inter-specific female sex pheromone components in vitro, and therefore could suggest that molecular discrimination in male response might reside within the behavioral pathway. Additional research is undoubtedly required to both dissect the molecular functions of PBPs in concert with cognate ORs with respect to ligand binding as well as the mechanisms that transmit neuronal signals which result in differential male responses to female emitted pheromones.

\section{Additional files}

Additional file 1: S1. The primers used for the PBPs expression. The lists of primers used for PBPs expression, and the digestion sites were underlined.

Additional file 2: S2. The message of sex pheromones used in binding assay. The sex pheromones messages used in binding experiment, including the molecular weight, purity and company.

Additional file 3: S3. The primers used for site-directed mutants. The lists of primers used for site-directed mutants, and the digestion sites were underlined.

Additional file 4: S4. The sequences of the wild type OfurPBP3 and the mutants. The nucleotide sequences of wild type OfurPBP3 and the mutants (OfurPBP3-m1, OfurPBP3-m2, OfurPBP3-m3 and OfurPBP3-m4).

\section{Authors' contributions}

TTZ, KLH and ZYW designed and conducted the research experiments. TTZ, KWW and BSC interpreted the results and drafted the manuscript. TTZ and YQS are the principal investigator who designed the experiment, analyzed the data and critically reviewed the manuscript. All authors read and approved the final manuscript. 


\begin{abstract}
Author details
${ }^{1}$ State Key Laboratory for the Biology of the Plant Diseases and Insect Pests, Institute of Plant Protection, Chinese Academy of Agricultural Sciences, No. 2 West Yuanmingyuan Road, Beijing 100193, China. ${ }^{2}$ College of Bioscience Technology, Shenyang Agriculture University, Shenyang, China. ${ }^{3}$ Department of Plant Sciences and Plant Pathology, Montana State University, Bozemon, MT 59717, USA. ${ }^{4}$ United States Department of Agriculture, Agricultural Research Service, Corn Insects and Crop Genetics Research Unit, lowa State University, Ames, IA 50011, USA
\end{abstract}

\section{Acknowledgements}

Not applicable.

\section{Competing interests}

The authors declare that they have no competing interests.

\section{Availability of data and materials}

All data generated or analyzed during this study are included in this published article [and its Additional files]

\section{Funding}

This work was supported by the National Natural Science Foundation of China (31201753) and Special Fund for Agro-scientific Research in the Public Interest (201303026). A portion of research data analyses and interpretation was supported by the United States Department of Agriculture, 565 Agricultural 566 Research Service (USDA-ARS; CRIS Project 3625-22000-017-00) and the lowa Agriculture 567 and Home Economics Experiment Station, Ames, IA (Project 3543).

\section{Received: 25 May 2016 Accepted: 16 January 2017}

Published online: 07 February 2017

\section{References}

1. Hansson BS. Olfaction in Lepidoptera. Experientia. 1995;51(11):1003-27.

2. Baker TC. Balanced olfactory antagonism as a concept for understanding evolutionary shifts in moth sex pheromone blends. J Chem Ecol. 2008;34(7):971-81.

3. Tegoni M, Campanacci V, Cambillau C. Structural aspects of sexual attraction and chemical communication in insects. Trends Biochem Sci. 2004;29(5):257-64.

4. Willett CS, Harrison RG. Insights into genome differentiation: pheromonebinding protein variation and population history in the European corn borer (Ostrinia nubilalis). Genetics. 1999;153(4):1743-51.

5. Vogt RG. Odorant binding protein homologues of the malaria mosquito Anopheles gambiae possible orthologues of the OS-E and OS-F OBPs of Drosophila melanogaster. J Chem Ecol. 2002;28(11):2371-6.

6. Xu YL, He P, Zhang L, Fang SQ, Dong SL, Zhang YJ, Li F. Large-scale identification of odorant-binding proteins and chemosensory proteins from expressed sequence tags in insects. BMC Genom. 2009;10(1):632.

7. Leal WS. Odorant reception in insects: roles of receptors, binding proteins, and degrading enzymes. Annu Rev Entomol. 2013;58:373-91.

8. Benton R, Vannice K, Vosshall L. An essential role for a CD36-related receptor in pheromone detection in Drosophila. Nature. 2007;450:289-93.

9. Damberger FF, Michel E, Ishida Y, Leal WS, Wüthrich K. Pheromone discrimination by a $\mathrm{pH}$-tuned polymorphism of the Bombyx mori pheromone-binding protein. Proc Natl Acad Sci. 2013;110(46):18680-5.

10. Cardé R, Roelofs W, Harrison R, Vawter A, Brussard P, Mutuura A, Munroe E. European corn borer: pheromone polymorphism or sibling species? Science. 1978;199(4328):555-6.

11. Yeh SF, Lee KC, Chang K-T, Yen F-C, Hwang J-S. Sex pheromone components from Asian corn borer, Ostrinia furnacalis (Hübner) (Lepidoptera: Pyralidae) in Taiwan. J Chem Ecol. 1989;15(2):497-505.

12. Fu X, Tabata J, Takanashi T, Ohno S, Tatsuki S, Ishikawa Y, Huang Y, Honda $H$. Female sex pheromone of Ostrinia orientalis - throwing a light on the relationship between 0 . orientalis and the European corn borer $O$. nubilalis. Chemoecology. 2004;14(3):175-80.

13. Huang $\mathrm{CH}$, Yan FM, Byers JA, Wang RJ, Xu CR. Volatiles induced by the larvae of the Asian corn borer (Ostrinia furnacalis) in maize plants affect behavior of conspecific larvae and female adults. Insect Sci. 2009;16(4):311-20.
14. Xue BY, Rooney AP, Kajikawa M, Okada N, Roelofs WL. Novel sex pheromone desaturases in the genomes of corn borers generated through gene duplication and retroposon fusion. Proc Natl Acad Sci. 2007;104(11):4467-72.

15. Allen JE, Wanner KW. Asian corn borer pheromone binding protein 3, a candidate for evolving specificity to the 12-tetradecenyl acetate sex pheromone. Insect Biochem Mol. 2011;41(3):141-9.

16. Rozen S, Skaletsky H. Primer3 on the www for general users and for biologist programmers. In: Misener S, Krawetz S, editors. Bioinformatics methods and protocols, vol. 132. New York: Humana Press; 1999. p. 365-86.

17. Zhang TT, Mei XD, Feng JN, Berg BG, Zhang YJ, Guo YY. Characterization of three pheromone-binding proteins (PBPs) of Helicoverpa armigera (Hübner) and their binding properties. J Insect Physiol. 2012;58(7):941-8.

18. Kruger NJ. The Bradford method for protein quantitation. New York: Humana Press; 2002.

19. Ban L, Zhang L, Yan Y, Pelosi P. Binding properties of a locust's chemosensory protein. Biochem Biophys Res Commun. 2002;293(1):50-4.

20. Zhang TT, Wang WX, Zhang ZD, Zhang YJ, Guo YY. Structure, binding characteristics, and 3D model prediction of a newly identified odorantbinding protein from the cotton bollworm, Helicoverpa armigera (Hübner). J Integr Agric. 2012;11(3):430-8.

21. Schwede T, Kopp J, Guex N, Peitsch MC. SWISS-MODEL: an automated protein homology-modeling server. Nucleic Acids Res. 2003;31(13):3381-5.

22. di Luccio E, Ishida Y, Leal WS, Wilson DK. Crystallographic observation of $\mathrm{pH}$-induced conformational changes in the Amyelois transitella pheromone-binding protein AtraPBP1. PLoS ONE. 2013;8(2):e53840.

23. Wu G, Robertson D, Brooks C, Vieth M. Detailed analysis of grid-based molecular docking: a case study of CDOCKER-A CHARMm-based MD docking algorithm. J Comput Chem. 2003;24(13):1549-62.

24. Maida R, Ziegelberger G, Kaissling KE. Ligand binding to six recombinant pheromone-binding proteins of Antheraea polyphemus and Antheraea pernyi. J Comp Physiol B. 2003;173(7):565-73.

25. Plettner E, Lazar J, Prestwich EG, Prestwich GD. Discrimination of pheromone enantiomers by two pheromone binding proteins from the gypsy moth Lymantria dispar. Biochemistry. 2000;39(30):8953-62.

26. Guo H, Huang LQ, Pelosi P, Wang CZ. Three pheromone-binding proteins help segregation between two Helicoverpa species utiliz ing the same pheromone components. Insect Biochem Mol Biol. 2012:42(9):708-16.

27. Rivière S, Lartigue A, Quennedey B, Campanacci V, Farine JP, Tegoni M, Cambillau C, Brossut R. A pheromone-binding protein from the cockroach Leucophaea maderae: cloning, expression and pheromone binding. Biochem Biophys Res Commun. 2003;371(2):573-9.

28. Hansson BS, Hallberg E, Löfstedt C, Steinbrecht RA. Correlation between dendrite diameter and action potential amplitude in sex pheromone specific receptor neurons in male Ostrinia nubilalis (Lepidoptera: Pyralidae). Tissue Cell. 1994;26(4):503-12.

29. Krieger J, Raming K, Breer H. Cloning of genomic and complementary DNA encoding insect pheromone binding proteins: evidence for microdiversity. BBA Gene Struct Expr. 1991;1088(2):277-84

30. Vogt RG, Rogers ME, Franco MD, Sun M. A comparative study of odorant binding protein genes: differential expression of the PBP1GOBP2 gene cluster in Manduca sexta (Lepidoptera) and the organization of OBP genes in Drosophila melanogaster (Diptera). J Exp Biol. 2002;205(6):719-44

31. Vogt RG, Callahan FE, Rogers ME, Dickens JC. Odorant binding protein diversity and distribution among the insect orders, as indicated by LAP, an OBP-related protein of the true bug Lygus lineolaris (Hemiptera, Heteroptera). Chem Senses. 1999;24(5):481-95.

32. Hooper AM, Dufour S, He X, Muck A, Zhou J-J, Almeida R, Field LM, Svatos A, Pickett JA. High-throughput ESI-MS analysis of binding between the Bombyx mori pheromone-binding protein BmorPBP1, its pheromone components and some analogues. Chem Commun. 2009;14(38):5725-7.

33. Deisig N, Kropf J, Vitecek S, Pevergne D, Rouyar A, Sandoz J-C, Lucas P, Gadenne C, Anton S, Barrozo R. Differential interactions of sex pheromone and plant odour in the olfactory pathway of a male moth. PLoS ONE. 2012;7(3):e33159.

34. Ochieng S, Park K, Baker T. Host plant volatiles synergize responses of sex pheromone-specific olfactory receptor neurons in male Helicoverpa zea. J Comp Physiol A. 2002;188(4):325-33. 
35. Große-Wilde E, Gohl T, Bouché E, Breer H, Krieger J. Candidate pheromone receptors provide the basis for the response of distinct antennal neurons to pheromonal compounds. Eur J Neurosci. 2007;25(8):2364-73.

36. Leary GP, Allen JE, Bunger PL, Luginbill JB, Linn CE, Macallister IE, Kavanaugh MP, Wanner KW. Single mutation to a sex pheromone receptor provides adaptive specificity between closely related moth species. Proc Natl Acad Sci. 2012;109(35):14081-6.

37. Zubkov S, Gronenborn AM. Byeon I-JL, Mohanty S: Structural consequences of the $\mathrm{pH}$-induced conformational switch in A. polyphemus pheromone-binding protein: mechanisms of ligand release. J Mol Biol. 2005;354(5):1081-90.
38. Pelton JG, Torchia DA, Meadow ND, Roseman S. Tautomeric states of the active-site histidines of phosphorylated and unphosphorylated IIIGlc, a single-transducing protein from Escherichia coli, using two-dimensional heteronuclear NMR techniques. Protein Sci. 1993;2(4):543-58.

39. Gong Y, Pace TCS, Castillo C, Bohne C, O'Neill MA, Plettner E. Ligand-interaction kinetics of the pheromone- binding protein from the gypsy moth, L. dispar: insights into the mechanism of binding and release. Chem Biol. 2009;16(2):162-72.

\section{Submit your next manuscript to BioMed Central and we will help you at every step:}

- We accept pre-submission inquiries

- Our selector tool helps you to find the most relevant journal

- We provide round the clock customer support

- Convenient online submission

- Thorough peer review

- Inclusion in PubMed and all major indexing services

- Maximum visibility for your research

Submit your manuscript at

www.biomedcentral.com/submit 